\title{
Students' organism state in conditions of distance learning
}

\author{
O.A. Dragich ${ }^{1,2}$, K.A. Sidorova ${ }^{1, *}$, T.A. Yurina ${ }^{1}$, E.V. Plotnikova ${ }^{1}$, and N.I. Akhshiyatova ${ }^{1}$ \\ ${ }^{1}$ Northern Trans-ural State Agricultural University, st. Republic, 7, 625003 Tyumen, Russia \\ ${ }^{2}$ Tyumen Industrial University, Volodarsky str, 38, 625000 Tyumen, Russia
}

\begin{abstract}
In the course of distance learning, the student is located remotely from his teacher, as well as from the educational institutions themselves. Such education is carried out mostly with the use of technologies for studying. Online learning contributes to improving the education quality due to the active implementation of the worldwide educational resources and a large share of independent work. A manifestation of negative impact of such education is stress caused not only by worries about coronavirus situation, but also by changes in the education field. Distance learning implies strict self-control, independence and consciousness of the student, ability to restrain their emotional states.
\end{abstract}

\section{Introduction}

Distance education is a form of education when the learning process is carried out in whole or partially via computer and telecommunication technologies and means. Due to such education, a scholar (student) is remoted from his teacher, as well as from educational institutions (schools, universities, colleges), educational tools and learning resources, for example, libraries. This kind of studying is carried out mainly with using of technical means, i.e. teaching process, methods, ways, information delivery are changed [1]. However, in addition to classical teaching tools, information from the Internet resources is actively used, and yet, old sources are also not forgotten. A common practice among teachers is sending educational materials to students, which include paper and electronic textbooks, often electronic duplicates of methodological instructions, stored up "since school days". When it comes to checking the students' knowledge, teachers take advantage of online testing, surveys and defense of work via video communication, consultations with the learning audience and communication with students through independent home work [2].

These changes are the major ones as a result of the transition to distance learning. Most of student and school routine has undergone changes. And these were only items directly related to studying. The usual everyday life has also changed. Therefore, the study of the students organism state in conditions of self-isolation is relevant. In this regard, the objective was set - to analyze the features of distance learning and their impact on the psychophysiological state of the body.

\footnotetext{
${ }^{*}$ Corresponding author: sidorova.clavdija@yandex.ru
} 


\section{Materials and Methods}

An analysis of the literature and reference material relating to distance learning for students has been carried out.

\section{Results and Discussion}

Since 1970s, distance education has been widespread in the United States and European countries. It does have some advantages over the old schools and ways of teaching; the beauty of this methodology is hidden in its name - anyone has the opportunity to educate themselves without being tied to their location. And in the larger scheme of things, regardless of nationality, a student can receive a diploma from a university in any country [3].

The majority of specialists in the educational environment believe that distance learning is a form that has a large potential and leaves a positive experience, since it suits many students, and is much cheaper in terms of cost. The use of the human achievements, the computer, made education technological and socially equal. $91 \%$ of students have access to the Internet. Such environment provides excellent opportunities for obtaining secondary and higher education, regardless of the health condition, age, residence, material security of the student. This form of education is consistent with the requirement for the education humanization, preparation of students in accordance with the strategy of "education of good" [4].

Learning process and the key to success are stand upon intensively controlled independent work. Everyone can determine a pace of studying, degree and quality of work, period of learning activity that satisfies their personal interests and needs, order and sequence of disciplines to master, a place for classes, and individual speed of learning. That is, it can be argued that the main advantage of the "remote learning" is a certain freedom, which makes it possible for distance learning to be in demand for those users who, for one reason or another, cannot study in usual conditions, but still want to get an education, increase the level of professional knowledge [5].

Distance learning allows one to improve the quality of education due to regular access to global educational resources, a fairly large percentage of independent work and the ability to search for material on a specific given topic, and this point is a kind of contribution to the future, as it instills useful skills and qualifications. These include independence, responsibility, organization, an objective estimation of one's own strengths, rapid adoption of a balanced decision, a reasonable assessment of the actions and the work done in general. These important traits can greatly help young people in moving up the ladder career [6].

When the scholars were just notified about the possible transition to online education, their faces lit up with an endless smile. Everyone was looking forward to a vacation, a lot of free time, hanging around and chatting with friends. Quarantine sounded like a rest. Many have forgotten that this time is devoted to maintaining their own health and continuing education. While the quarantine itself was managed with the aim of isolating people from society and society from people. Although currently there is no need to spend time on the road to the educational building, on lessons and breaks, for students on double classes and breaks, respectively, no one canceled the educational hours. At some institutions, the attendance of Internet classes is carefully monitored, special departmental documents are drawn up, both the students themselves and administration of the university are notified. However, it should be noted that almost all measures are aimed at improving the education quality and information assimilation, but excessive workload can affect the health of students [7]. 
Distance learning practice was not widespread before the epidemic, but due to the emerged circumstances, the distance learning arose and its consequences, like a train, pulled after it. There are several negative aspects caused by the transition to a new level of education. This is manifested in the fact that going out into the street became impossible not only because of quarantine measures, but also because of the lack of personal time that could be devoted to strolling, going out in the open air.

At first, it was not clear to the students or the teachers exactly how to conduct classes, the format of homework to give and way to control it. All of that was complicated by inability of some teachers to use technology, as well as the impossibility to react to emerging problems in timely manner. And there was no lack either in problems, and in questions. The websites where educational material was uploaded did not always work stably. Their organization also left much to be desired. The platform for the classes was also not chosen immediately. Along with this, teachers began to give a significant amount of assignments; and taking into account the fact that students already have a sufficient number of disciplines, in this case the student spends much more time on independent work, although before the pandemic the volume of tasks were leaving space for allocating time for their own leisure and rest.

Another manifestation of the negative impact of this education is a stressful state. Moreover, stress caused by not only experiences from the virus situation, but also from changes in the field of education. University students adapt to teachers, to their manner of presenting information, to the environment of teamwork, to the daily routine on weekdays. Now students are forced (like the teachers themselves, of course) to sit at least 4-5 hours at the monitors just to attend lectures. While doing independent work, this routine continues, but in a secluded place. On the Internet, there is no such thing as one-on-one communication, now it is impossible to imagine that a teacher or classmate can be approached with any question and to solve it right at the moment. One can object by saying that there are messengers for this. But as a rule, everyone answer with delay and very succinctly, and any attempts to repeat the question for clarification cause a feeling of importunity both for the sender of the message and for the recipient. Thus, one has to figure out the information oneself, and one should not rely on anyone's help. In general, stressful tension can emerge for several reasons. It is necessary to try as much as possible to adapt to the changed conditions.

The most important organ for obtaining visual information about the environment, one of the five basic human senses, is vision. The eyes are exposed to great stress on a daily basis. When visiting the university in the lecture hall as they are, students switch their attention from one object to another - a notebook, a teacher, snow outside the window. All of these focus movements relieve eye strain, and as a result, they get fatigue more slowly. Now the object of observation is limited only by the screen and sheets of notes. In the current conditions, it is difficult to change anything, and therefore it is worth worrying about the state of your own vision. The advice is, as always, common and simple whenever possible, although it is not always feasible, at least spend leisure time not in front of the monitor and periodically do exercises for the eyes.

It is worth recognizing that the pandemic has greatly affected such an important aspect of people's lives as physical activity. It has undoubtedly decreased greatly these days. If previously the student had to think about the route through the city to the university, transitions from one building to another, from office to office, going out for lunch, physical education, now the movement is limited to a couple of movements from table to refrigerator, to bathroom, and again to the table, and in the evening the main thing is to get to the bed. Earlier it was possible to balance the amount of calories assimilated and consumed, but at this time, regular staying at home or in dormitory limits the actions of students. Overwhelming majority of students lost most of the muscular activity and only 
mental activity remained, which, alas, is not enough. This type of studying does not imply the movement of a student from one location to another, which is why the only brain activity is insufficient.

Another factor is not conducive to health - many people have begun to "comfort eat". This has happened to everyone, when the feeling of hunger comes much earlier to the cerebral cortex than the actual starvation. Most often, a snack is a thing, since it that does not require time-consuming preparation, so satiety comes quickly. It is extremely important to avoid such foods during isolation as they are harmful to the body. In addition, in the absence of movement, there are risks of gaining excess weight. The diet must be balanced correctly in order to gain energy for learning. It is advisable to plan all meals in advance so as not to be distracted by them during the educational process.

Since the concept of distance learning is no longer new, both in Russia and in adjacent countries, certain scientific researches have been carried out that allows us to analyze the specifics of this phenomenon.

The cognitive characteristics of remote forms of learning have been studied to the best degree. The goal of any type of study is to achieve the learner's assimilation of the learnt material, which becomes possible when the word is associated with an image, then visualization occurs through the demonstration of the studied material, which are actively used in distance learning.

The studies carried out indicate that the specificities of distance education impose certain requirements to the methods and functions of planning classes and implementing decisions. In addition, this system is based on certain characteristics of students' attention, memory and thinking.

It is worth highlighting separately the perception speed of information, which in this period is controlled exclusively by the students themselves, depending on concentration, personal preferences and other circumstances. However, some began to spend more and others less time on learning. But any responsible student assimilates the information he needs in his own time, and memorization of this material is much faster. Such a learning process develops freedom and flexibility of thinking, and also contributes to independent planning and organization of activities and work schedule. In such conditions, teachers strive to attract students to personal imagination, thereby raising individual creativity to a new level, by creating comfortable conditions for creative self-expression.

In addition to certain changes in the cognitive sphere, learning at a distance has influenced the psychoemotional state [8]. The emotionality of a person affects any actions and interactions in people's lives, being an integral part of it, including experiences, affective states or emotional impulses. During the analysis of the comparison of psychoemotional states and human experiences in foreign and domestic studies, a special influence of psychoemotional states of a negative kind on health was revealed.

Distance education affects scholars and their psychoemotional state, one of the negative factors is the lack of direct personal communication between students and the teacher, the inability to contact directly, this means that all items based on an individual approach and upbringing are canceled. This, of course, is a negative aspect for life and learning, since a student does not have a mentor to emotionally nourish, raise morale, brighten up the learning process, attract and spark the interest.

Distance learning implies strict self-control, which is directly related to the independence and consciousness of the student. The student is required to be composured, and as a matter of course there is the ability to control their emotional states.

The epidemiological situation in the country and abroad has reproduced a new reality in the field of education and has created discussions about the effectiveness of distance learning. It is impossible to give an unambiguous answer to the question of the distance education quality today. As they usually say in such cases, time will tell. And this is true. 
But the questions of completely changed stereotypes of the relationship between students and teachers of educational institutions in relation to their physiological adaptation to new learning conditions and possible health risks require an immediate answer.

Etiological factors of mental and psychosomatic diseases are climatic peculiarities, restrictions on communication and movement of people, monotony of the environment and situation, as well as a lack of sun, heat and light, and, accordingly, vitamins. While distance learning has greatly reduced, if not eliminated, face-to-face communication, especially during the first period of quarantine, it has also increased the intensity of virtual reality communication. Of course, it took some effort to get used to this behavior model, and one had to adapt to this too [9].

Mental health has been proven to have a huge impact on how a person feels physically. Frequent emotional stress, nervous disorders, shocks, squabbles and scandals can mess the following diseases: psoriasis (the disease is practically incurable, symptoms tend to return with the slightest repeated stress), stomach ulcers, diabetes mellitus, which can occur after a severe shock, heart attacks and strokes.

If one will not take preventive measures, there is a chance of developing pathological processes such as panic attacks, depression, heart failure, stomach ulcers, hypertension, anorexia. Also, a nervous state can cause activity and motivation decrease.

\section{Conclusion}

Suchwise, various types of education systems have their own positive and negative attributes that affect the state of the student's organism. The distance learning system exposes the following features: limitation of motor activity; individual studying; freedom and flexibility of time management; accessibility for everyone; social equality, creativity; ability to control emotional state; minimal stressful situations; consciousness and independence of the student. The traditional education system has other traits: live communication between students and teachers, but at the same time a strong stressful stress on tests, pretests, exams and seminars; creativity is also present; methodological and ideological orientation is very pronounced, which develops the motivation for learning; it is characterized by the correct choice and application by the teacher of various sources of knowledge acquisition for students; flexibility of the methods used.

\section{References}

1. N.Ya. Prokopiev, A.M. Durov, E.A. Semizorov, S.I. Khromina, D.S. Rechapov, Scientific notes of the University named after P.F. Lesgafta, 5(183), 362 (2020)

2. V.M. Krylov, A.V. Krylova, T.A Ponomareva, Kazan social and humanitarian bulletin, 6(47), 43 (2020)

3. K.A. Sidorova, O.A. Dragich, T.A. Yurina, O.M. Trushik, E.A. Berseneva, Natural and technical sciences, 11(149), 115 (2020)

4. O.A. Dragich, K.A. Sidorova, R.R. Timkanov, O.M. Trushik E.A. Berseneva, Natural and technical sciences, 12(138), 135 (2019)

5. O.A. Dragich, N.N. Ryabova, K.A. Sidorova, Materials of the International scientificpractical conference "Educational-patriotic and physical culture-sports activities in universities: innovations in solving urgent problems", 98 (2017)

6. T.A. Yurina, K.A. Sidorova, Materials of the All-Russian scientific and methodological conference "Strategy for the development of sports-mass work with students", 142 (2015) 
7. O. Dragich, K. Sidorova, S. Pashayan, L. Glazunova, N. Cheremenina, T. Sidorova, E. Ivakina, S. Zobnina, V. Domatsky, et al, Journal of Physical Education and Sport, 18, 1108 (2018)

8. O.A. Dragich, E.A. Klyushnikova, K.A.Sidorova, N.A. Cheremenina, N.A. Tatarnikova, Journal of Environmental Management and Tourism, 8(32), 1679 (2018)

9. O.N. Goncharenko, E.P. Krasnolobova, N.A. Cheremenina, K.A. Sidorova, S.A. Veremeeva, Astra Salvensis, 6, 647 (2018) 